Kapitalertragsteuer und Abgeltungsteuer verstehen 
Oliver Rhodius • Johannes Lofing

\section{Kapitalertragsteuer und Abgeltungsteuer verstehen}

Besteuerung von Kapitalerträgen im Privatvermögen

2., aktualisierte und erweiterte Auflage

照 Springer Gabler 
Oliver Rhodius

Marburg

Deutschland
Johannes Lofing

Eschborn

Deutschland

Die Deutsche Nationalbibliothek verzeichnet diese Publikation in der Deutschen Nationalbibliografie; detaillierte bibliografische Daten sind im Internet über http://dnb.d-nb.de abrufbar.

\section{Springer Gabler}

(c) Springer Fachmedien Wiesbaden 2013

Das Werk einschließlich aller seiner Teile ist urheberrechtlich geschützt. Jede Verwertung, die nicht ausdrücklich vom Urheberrechtsgesetz zugelassen ist, bedarf der vorherigen Zustimmung des Verlags. Das gilt insbesondere für Vervielfältigungen, Bearbeitungen, Übersetzungen, Mikroverfilmungen und die Einspeicherung und Verarbeitung in elektronischen Systemen.

Die Wiedergabe von Gebrauchsnamen, Handelsnamen, Warenbezeichnungen usw. in diesem Werk berechtigt auch ohne besondere Kennzeichnung nicht zu der Annahme, dass solche Namen im Sinne der Warenzeichen- und Markenschutz-Gesetzgebung als frei zu betrachten wären und daher von jedermann benutzt werden dürften.

Gedruckt auf säurefreiem und chlorfrei gebleichtem Papier

Springer Gabler ist eine Marke von Springer DE. Springer DE ist Teil der Fachverlagsgruppe Springer Science+Business Media.

www.springer-gabler.de 


\section{Vorwort}

Mit der Einführung der Abgeltungsteuer als Teil der Unternehmensteuerreform 2008 begann 2009 eine neue Zeitrechnung für Kunden und Banken. Das erklärte Ziel der Abgeltungsteuer: Die Besteuerung von Kapitalerträgen einfacher zu gestalten. Doch ist die neue Besteuerungssystematik wirklich einfacher geworden? Generell kann man nach nunmehr fast fünf Jahren sagen, dass die Umsetzung der Abgeltungsteuer schwieriger zu bewältigen war, als man es sich gedacht hatte. Noch heute sind nicht alle Zweifelsfragen geklärt, diese müssen sukzessive mit der Finanzverwaltung abgestimmt werden.

Sehr problematisch bleiben weiterhin Themen rund um das Veranlagungsverfahren, die Anrechnung ausländischer Quellensteuer oder die Besteuerung von Investmentfonds. Oft wird bemängelt, dass die gesetzlichen Anforderungen nicht mit der Bankpraxis vereinbar sind und eine vollumfängliche Anwendung der Abgeltungsteuer in vielen Fällen bei Banken gar nicht möglich ist. Besonders deutlich wird dies bei der Besteuerung von Investmentfonds, wo es durch zahlreiche Sonderregelungen im Investmentsteuergesetz zu einer erheblichen Verkomplizierung des Steuereinbehaltes kommt und Kunden in vielen Fällen gar nicht am Gang zum Finanzamt vorbeikommen.

Aus heutiger Sicht steht fest, dass die Einführung der Abgeltungsteuer nicht zu den gewünschten Vereinfachungen geführt hat, wie sie sich Banken und Kunden gewünscht haben. Sofern Kunden außer Konten auch Depots bei ihren Banken unterhalten, wird es oft schwer, den Überblick über die steuerlichen Berechnungen und Buchungen zu behalten, da Banken seit 2009 eine sehr umfangreiche Verlustverrechnung praktizieren und sogenannte steuerliche Optimierungen von Kunden oft nur schwer nachvollzogen werden können. Bei umfangreichen Depotbewegungen, wie dies z.B. bei Vermögensverwaltungen üblich ist, fällt die Nachvollziehbarkeit der steuerlichen Verlustverrechnung im Nachhinein sogar der depotführenden Bank selbst oft nicht leicht.

Da seit 2007 fortwährend an den gesetzlichen Grundlagen und Anwendungserlassen gearbeitet wird, ist es fast unmöglich einen allumfassenden Überblick über die steuerlichen Regelungen der Abgeltungsteuer zu behalten. Auch im Jahr 2013 gibt es wieder diverse Änderungen für die Banken zu beachten. U.a. wurde das umfassende Anwendungsschreiben zur Abgeltungsteuer von der Finanzverwaltung ergänzt bzw. überarbeitet. Weiterer Anpassungsbedarf ergibt sich zudem aus dem Jahressteuergesetz 2013 bzw. aus dem Amtshilferichtlinie-Umsetzungsgesetz.

Dieses Fachbuch soll die Anwendung der Abgeltungsteuer und somit auch die Berechnung der Kapitalertragsteuer aus Sicht der Bankpraxis wiedergeben. Hierbei wird detailliert auf die Herleitung steuerlicher Bemessungsgrundlagen eingegangen. Viele Praxisbeispiele und eine verständliche Struktur verdeutlichen die Anwendung des neuen Steuerrechts. Außerdem gibt eine FAQ-Liste am Ende jedes einzelnen Kapitels schnelle Antworten auf die wichtigsten Fragen rund um das Thema Abgeltungsteuer. 
Relevante BMF-Schreiben, auf die im Buch verwiesen wird, stehen auf www.springergabler.de zum kostenlosen Download bereit.

Nicht Bestandteil dieses Buches sind Ausführungen zur Besteuerung im Betriebsvermögen, zur Erbschafts- bzw. Schenkungsteuer sowie zu steuerlichen Behandlung von Kapitalmaßnahmen.

Das Buch basiert auf dem Rechtsstand vom März 2013. Aufgrund des ständigen Wandels der dargestellten Rechtsmaterie sind die Aussagen grundsätzlich auf ihre Aktualität hin zu prüfen. Der Inhalt des Buches wurde von den Autoren sorgfältig recherchiert; die aufgeführten Beispiele dienen lediglich zur Verdeutlichung der beschriebenen Thematik. Das Werk kann eine Steuer- bzw. Rechtsberatung zu den einzelnen Themengebieten nicht ersetzen.

Die Autoren bedanken sich ganz herzlich bei Herrn Gunther Manske für die konstruktive Unterstützung beim Korrekturlesen des Buches.

Für Anmerkungen, Fragen oder Kritik zu diesem Buch steht Ihnen folgende Email-Adresse zur Verfügung: kontakt@abgeltungsteuerbuch.de

Wir freuen uns auf Ihre Rückmeldungen. 


\section{Inhaltsverzeichnis}

Vorwort

1.2 Gesetzliche Grundlagen und wichtige Anwendungsschreiben der Finanzverwaltung zur Abgeltungsteuer......

1.3 Die $\S \S 20$ und 23 EStG im alten und neuen Steuerrecht ..........................................19

1.4 Kapitalerträge, die niemals der Abgeltungsteuer unterliegen ................................20

$1.5 \quad$ Kapitalerträge mit Wahlrecht zur tariflichen Einkommensteuer.............................21

1.6 Kapitalerträge mit Pflichtveranlagung zum Abgeltungssteuersatz ......................21

1.7 Freiwillige Veranlagung der Kapitalerträge durch den Steuerpflichtigen .............22

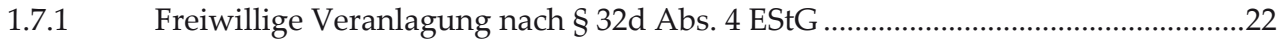

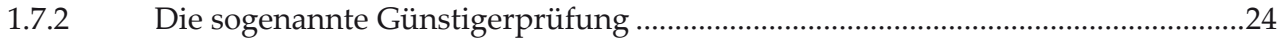

1.8 Der Abzugsverpflichtete der Kapitalertragsteuer ................................................26

1.9 Der Zufluss von Kapitalerträgen und der Zeitpunkt des Kapitalertrag-

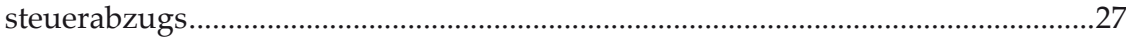

1.10 Die Kirchensteuer als Zuschlagsteuer zur Kapitalertragsteuer..............................28

1.10.1 Von der Bank anzuwendende Kirchensteuersätze...................................................29

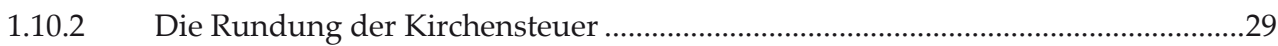

1.10.3 Bescheinigung der Kapitalertragsteuer zur Veranlagung der Kirchensteuer .......29

1.10.4 Kirchensteuer bei Personengemeinschaften ohne gemeinsame Veranlagung.......30

1.10.5 Kirchensteuerabzug bei Ehegatten .......................................................................

1.10.6 Kirchensteuerabzug bei Personengesellschaften und Treuhandkonten .................31

1.10.7 Kapitalertragsteuer und Kirchensteuer - eine besondere Rechnung ......................31

1.10.8 Automatisierter Kirchensteuerabzug durch die Banken ab 2015............................35

$1.11 \quad$ Fragen und Antworten zu Kapitel 1 .......................................................................

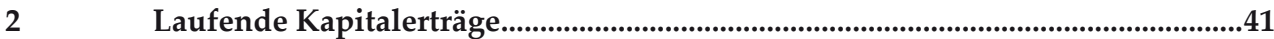

2.1 Grundlagen zur Besteuerung von laufenden Kapitalerträgen ...............................41

2.1.1 Kapitalerträge, die dem abgeltenden Kapitalertragsteuerabzug unterliegen ........41

2.1.2 Kapitalerträge, die der Abgeltungsteuer, jedoch nicht der Kapitalertragsteuer

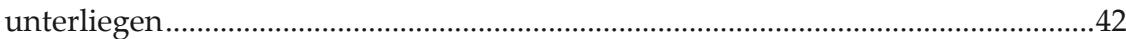

2.1.3 Kapitalerträge, die nicht der Abgeltungsteuer, aber dem Kapitalertragsteuerabzug unterliegen .............................................................................................42

2.2 Die Besteuerung von Dividenden und dividendenähnlichen Erträgen..................43

2.2.1 Die steuerliche Behandlung von inländischen Dividenden......................................44

2.2.1.1 Steuerliche Änderungen durch das OGAW-IV-Umsetzungsgesetz........................45

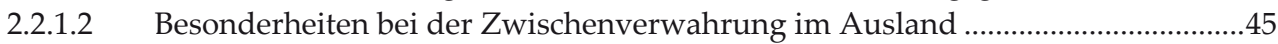

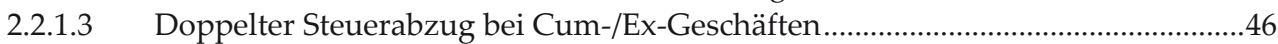


2.2.1.4 Nur einmaliger Steuerabzug bei Lieferung von Stücken mit Dividendenspruch .....47

2.2.1.5 Besonderheiten bei Steuerausländern ......................................................................4

2.2.1.6 Anwendung für REIT-Aktiengesellschaften, ADRs, GDRs und IDRs ....................50

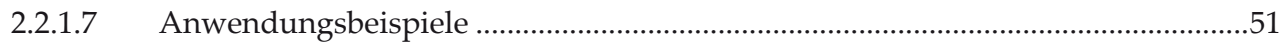

2.2.1.8 Auswirkung auf die Anmeldung und Abführung der Kapitalertragsteuer ..........58

2.2.2 Die steuerliche Behandlung von ausländischen Dividenden ..................................58

2.2.2.1 Die Berechnung der Kapitalertragsteuer unter Anrechnung ausländischer

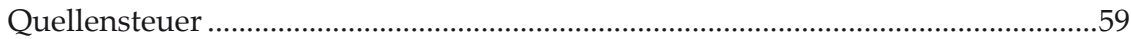

2.2.3 Dividenden aus dem steuerlichen Einlagekonto ( $§ 27 \mathrm{KStG})$..................................60

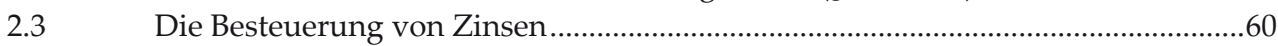

$2.4 \quad$ Die Besteuerung von inländischen Wandelanleihen, Genussrechten und

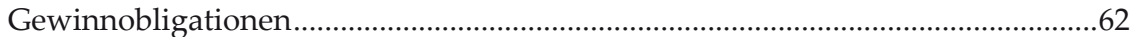

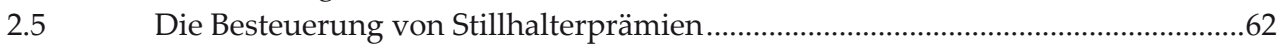

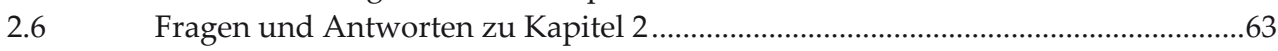

3 Die Besteuerung von Erträgen aus der Veräußerung oder Endfälligkeit von Wertpapieren ..............................................................................................................................65

3.1 Grundzüge der Besteuerung von Erträgen aus der Veräußerung oder

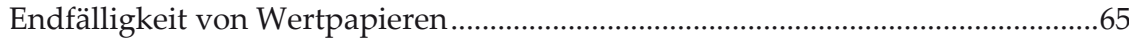

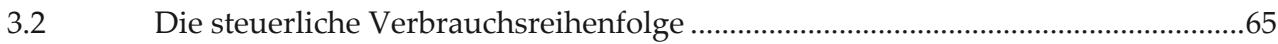

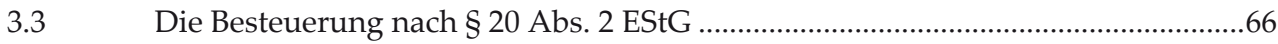

3.4 Wegfall der sogenannten Spekulationsfrist im neuen $\S 20$ Abs. 2 EStG ................67

3.5 Die Ermittlung des Ertrages nach $\S 20$ Abs. 2 EStG ................................................67

3.6 Der steuerliche Zuflusszeitpunkt bei Veräußerung und Endfälligkeit von

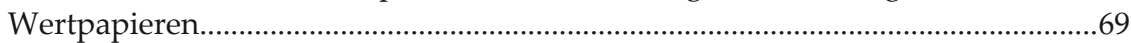

3.6.1 Steuerlicher Zufluss bei Veräußerungen von Wertpapieren ...................................69

3.6.2 Steuerlicher Zufluss bei Endfälligkeiten von Anleihen ...........................................70

3.6.3 Steuerlicher Zufluss bei Endfälligkeiten von Zertifikaten .......................................70

3.7 Übergangsregelungen für die Anwendung von $\S 20$ Abs. 2 EStG..........................70

3.7.1 Übergangsregelungen bei Aktien, REIT-AGs sowie ADRs, GDRs und IDRs ........71

3.7.2 Übergangsregelungen bei Anleihen mit steuerlichem Bestandsschutz

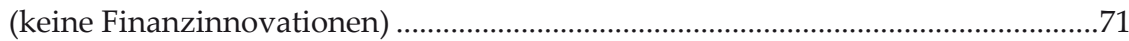

3.7.3 Keine Übergangsregelungen bei sogenannten Finanzinnovationen .......................72

3.7.4 Übergangsregelungen bei Zertifikaten...................................................................

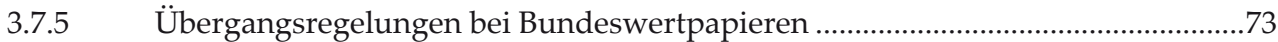

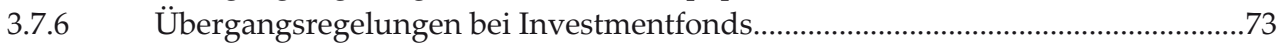

3.7.6.1 Besonderheiten bei steueroptimierten Geldmarktfonds ..........................................74

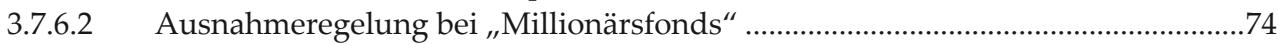

3.8 Die Pauschalbesteuerung bei fehlenden Anschaffungskosten ................................75

3.9 Die Korrektur von pauschalen Bemessungsgrundlagen ..........................................76

3.10 Stückzinsen bei Kauf und Verkauf .........................................................................77

3.10.1 Stückzinsen bei Altfällen mit steuerlichem Bestandsschutz .....................................78

3.10.2 Stückzinsen bei Neufällen oder Anleihen ohne steuerlichen Bestandsschutz.......79

3.11 Die Besteuerung nach § 23 EStG seit dem Jahr 2009 ..............................................80 


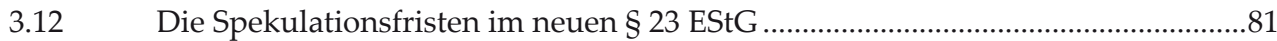

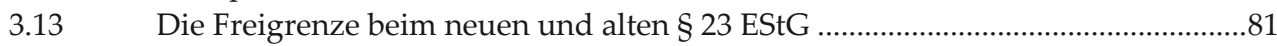

3.14 Keine Wirkung von Freistellungsaufträgen oder NV-Bescheinigungen bei

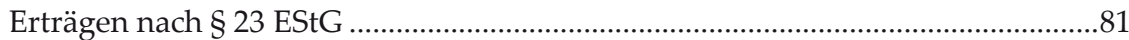

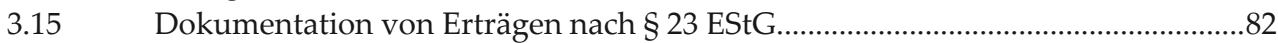

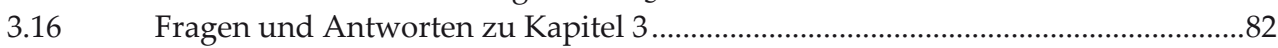

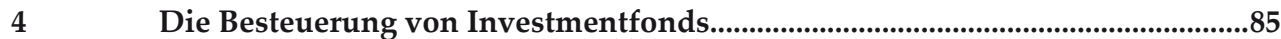

4.1 Die Rechtsgrundlagen zur Besteuerung von Erträgen aus Investmentfonds ........85

4.2 Die Unterscheidung von Investmentfonds unter steuerlichen Aspekten...............86

4.3 Die Meldung der Besteuerungsdaten durch WM ..................................................86

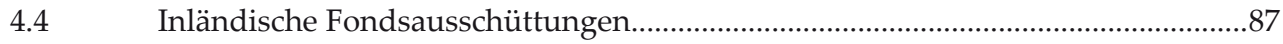

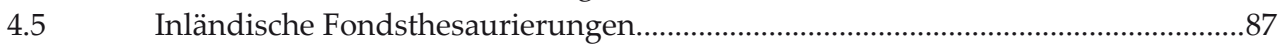

4.5.1 Die Ermittlung des für die Abrechnung der Thesaurierung relevanten

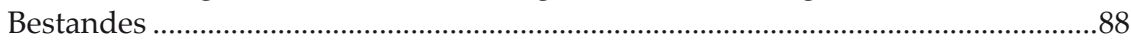

4.5.2 Die Neuerung durch das OGAW-IV-Umsetzungsgesetz......................................89

4.5.3 Die Zwischenverwahrung im Ausland bei inländischen, thesaurierenden

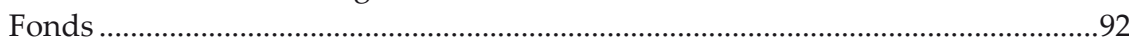

4.5.3.1 Die Zwischenverwahrung im Ausland bei inländischen, thesaurierenden Fonds bei cum belieferten Beständen .......................................................................94

4.5.3.2 Die Zwischenverwahrung im Ausland bei inländischen, thesaurierenden Fonds bei nicht cum belieferten Beständen .........................................................97

4.6 Ausländische Fondsausschüttungen ....................................................................101

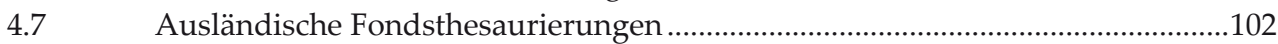

4.7.1 Die Ermittlung des für die Abrechnung der ausländischen Thesaurierung

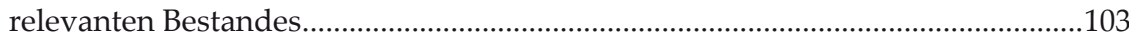

4.7.2 Die Besonderheiten des Kapitalertragsteuerabzuges bei ausländischen

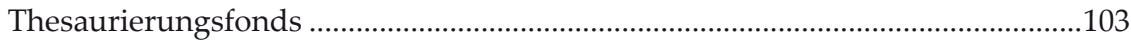

4.7.3 Die Systematik der akkumulierten ausschüttungsgleichen Erträge ......................105

4.7.4 Der Ersatzwert für fehlende ausschüttungsgleiche Erträge .................................107

4.7.5 Besonderheiten bei ISIN-Wechsel oder steuerneutralen Fondsfusionen ..............109

4.7.6 Besonderheiten bei Teilthesaurierungen von Fonds .............................................110

4.8 Intransparente Fonds und deren besondere steuerliche Behandlung...................111

4.8.1 Die akkumulierten Mehrbeträge bei intransparenten Fonds.................................112

4.8.2 Statusänderungen von steuerlicher Transparenz zu Intransparenz

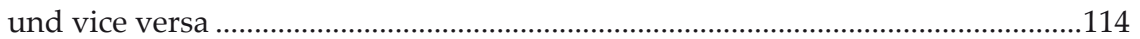

4.9 Die steuerliche Behandlung von Zwischengewinnen...........................................114

4.9.1 Grundlagen der Zwischengewinnbesteuerung .....................................................114

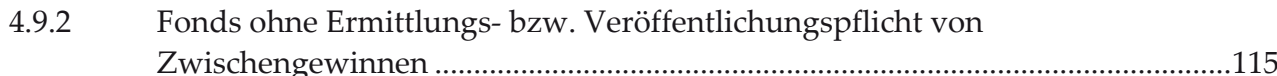

4.9.3 Unregelmäßige Veröffentlichung von Zwischengewinnen ..................................115

4.9.4 Der Ersatzwert für den fehlenden Zwischengewinn .............................................116

4.9.5 Berücksichtigung gezahlter Zwischengewinne nur bei Durchführung des Ertragsausgleichsverfahrens. 
4.10 Die Berechnung von Veräußerungsergebnissen bei Fonds .119

4.10.1 Zwischengewinne als Korrekturgröße bei der Berechnung von

Veräußerungsergebnissen

4.10.2 Immobiliengewinne als Korrekturgröße bei der Berechnung von Veräußerungsergebnissen

4.10.3 Thesaurierungserträge als Korrekturgröße bei der Berechnung von Veräußerungsergebnissen

4.10.4 Mehrbeträge intransparenter Fonds als Korrekturgröße bei der Berechnung von Veräußerungsergebnissen .

4.10.5 Sonstige Bereinigungsfaktoren bei der Berechnung von Veräußerungsergebnissen

4.10.6 Zusammenfassung der Bereinigung von Veräußerungsergebnissen....................127

4.10.7 Ersatzbemessungsgrundlage nach § 43a Abs. 2 S. 7 EStG und nachholender Steuerabzug nach $\S 7$ Abs. 1 S. 1 Nr. 3 InvStG bei fehlenden Anschaffungsdaten ... 128

$4.11 \quad$ Fragen und Antworten zu Kapitel 4

5

Die Abstandnahme vom Kapitalertragsteuerabzug. . .135

5.1 Die verschiedenen Arten der Abstandnahme vom Kapitalertragsteuerabzug...135

$5.2 \quad$ Der Freistellungsauftrag bzw. Sparer-Pauschbetrag .............................................136

5.2.1 Der Sparer-Pauschbetrag bei natürlichen Personen..................................................138

5.2.2 Die Wirkungsweise des Freistellungsauftrages ...................................................139

5.2.3 Die steuerliche Identifikationsnummer bei Freistellungsaufträgen ......................141

5.2.4 Freistellungsaufträge mit einem Freistellungsvolumen von null .........................142

$5.3 \quad$ Der Körperschaftsteuerfreistellungsbescheid .......................................................142

5.3.1 Die Wirkungsweise von Freistellungsbescheiden .................................................143

5.4 Die vorläufige Bescheinigung über die Gemeinnützigkeit ....................................146

5.4.1 Die Wirkungsweise von vorläufigen Bescheinigungen über die Gemeinnützigkeit

5.5 Die Anlage zum Körperschaftsteuerbescheid .....................................................149

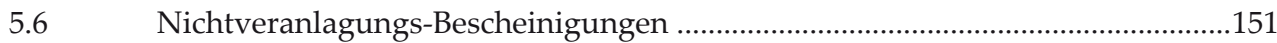

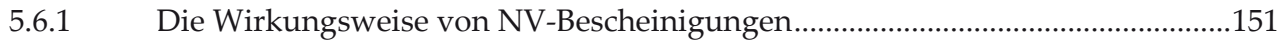

5.6.2 NV-Bescheinigungen für natürliche Personen..................................................152

5.6.3 NV-Bescheinigungen für steuerbefreite Körperschaften und inländische juristische Personen des öffentlichen Rechts....

5.6.4 NV-Bescheinigungen für steuerbefreite Körperschaften, die gemeinnützigen, mildtätigen oder kirchlichen Zwecken dienen ......................................................156

5.6.4.1 Die Wirkungsweise der NV02-Bescheinigung mit der Art 03 ...............................156

5.6.4.2 Die Wirkungsweise der NV02-Bescheinigung mit den Arten 02 und 03.............158

5.6.5 NV-Bescheinigungen für steuerbefreite Zweckverbände, Städte und Gemeinden

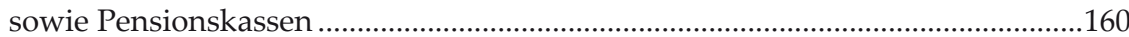

5.6.5.1 Die Wirkungsweise der NV02-Bescheinigung mit der Art 04 ................................160

5.6.5.2 Die Wirkungsweise der NV02-Bescheinigung mit den Arten 02 und 04.............162

5.6.5.3 Gleichzeitige Erteilung einer NV02-Bescheinigung mit der Art 02 bei Beantragung einer NV02-Bescheinigung mit den Arten 03 oder 04. 
5.6.6 NV-Bescheinigungen für Investmentvermögen .164

5.6.7 Dauerüberzahlerbescheinigungen für Versicherungsunternehmen, Vermögensverwaltungen und Holdinggesellschaften ..... 167

5.6.8 Die freibetragsabhängige NV-Bescheinigung nach § 24 Abs. 1 KStG ..................169

5.7 Die Freistellungserklärung bei betrieblichen Erträgen ...........................................171

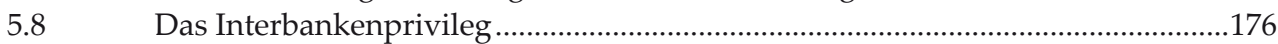

5.8.1 Identität von Gläubiger und Schuldner der Kapitalerträge ...................................178

5.9 Steuerausländer (beschränkt steuerpflichtige Personen) ........................................180

5.10 Die Abstandnahme auf Grund Rechtsform ..........................................................182

5.11 Abstandnahme bei losen Personenzusammenschlüssen ..........................................185

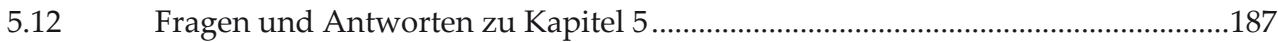

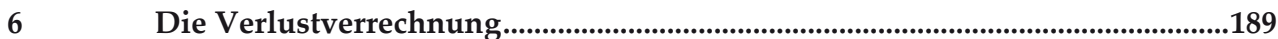

6.1 Die Verlustverrechnung im Privatvermögen ..........................................................189

6.2 Ermessensspielräume bei der bankseitigen Verlustverrechnung ..........................190

6.3 Die Verrechnung von Altverlusten........................................................................190

6.4 Einschränkungen der Verrechnung von Verlusten aus Kapitalvermögen im

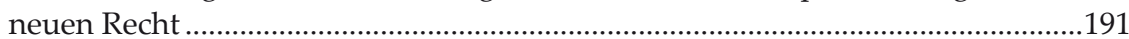

6.5 Die Verlustverrechnung auf Ebene der Bank ....................................................192

6.6 Die Definition von Aktien im Sinne der Verlustverrechnung .................................. 195

6.7 Berücksichtigung von Verlusttöpfen, Freistellungsauftrag und Quellensteuer .... 196

6.8 Die Verlustverrechnung bei Treuhandkonten und -depots ...................................... 197

6.9 Die Verlustverrechnung bei Ehegatten ...................................................................... 198

6.10 Die übergreifende Verlustverrechnung bei Ehegatten ab 2010 ................................ 199

6.11 Die Verlustverrechnung bei nicht ehelichen Gemeinschaftskonten und -depots.... 201

6.12 Die Verlustverrechnung bei Tod eines Kunden.....................................................201

6.13 Verlustverrechnungstöpfe bei Vorliegen einer Nichtveranlagungs-

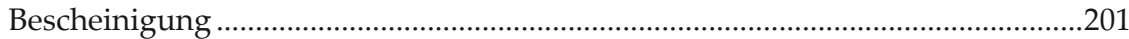

6.14 Das Führen von Verlustverrechnungstöpfen bei Steuerausländern......................201

6.15 Durchführung der Verlustverrechnung nur bei Privatvermögen .........................202

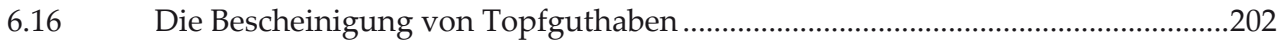

6.16.1 Die Übertragung von Topfguthaben an andere Banken ......................................203

6.16.2 Anwendungsbeispiele zu Verlusttopfüberträgen ..................................................204

6.17 Die steuerliche Optimierung im Rahmen der Verlustverrechnung ......................205

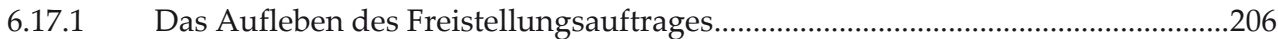

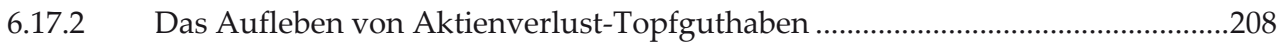

6.17.3 Das Aufleben des Quellensteuertopfes .................................................................211

6.17.4 Die Erstattung von gezahlten Steuern bei der Verlustverrechnung ......................213

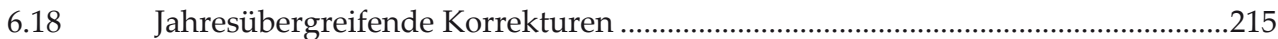

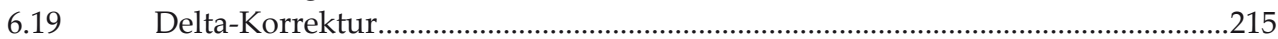

6.19.1 Keine Anwendung der Delta-Korrektur bei bestimmten Sachverhalten.............216

6.19.2 Veranlagung bei nicht durchgeführter Delta-Korrektur .......................................217

6.19.3 Karenzzeit bei der Anwendung der Delta-Korrektur ............................................217

6.19.4 Zeitpunkt des Zuflusses bei Delta-Korrekturen ......................................................217 


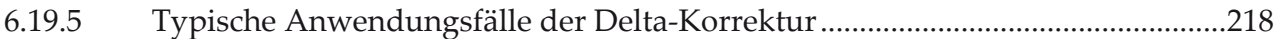

6.19.6 Die technische Umsetzung der Delta-Korrektur in der Bankpraxis .....................218

6.19.7 Anwendungsbeispiele für die Delta-Korrektur ....................................................219

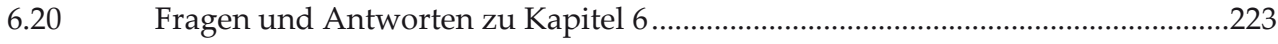

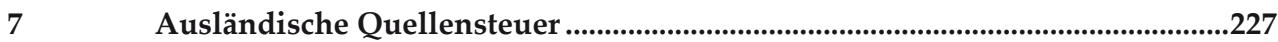

7.1 Gesetzliche Grundlagen der Quellensteueranrechnung .....................................227

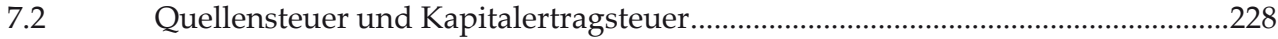

7.3 Rückforderung und Vorabbefreiung von Quellensteuer .......................................229

7.4 Anrechenbare Quellensteuer nach DBA ...............................................................2230

7.5 Anrechnung von Quellensteuer nach DBA in Konkurrenz zu nationalen

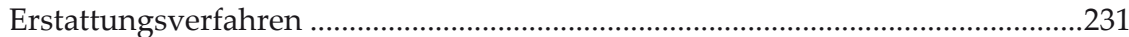

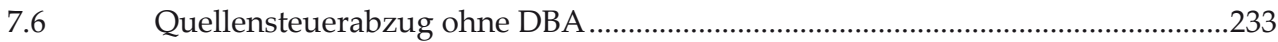

7.7 Die Anrechnung fiktiver Quellensteuer...............................................................22

7.7.1 Bedingungen für die Anrechnung fiktiver Quellensteuer ....................................235

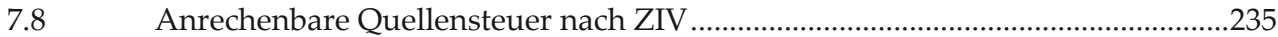

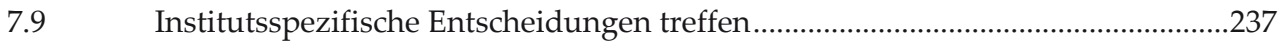

7.10 Quellensteuer Fondseingangs- und Fondsausgangsseite .....................................237

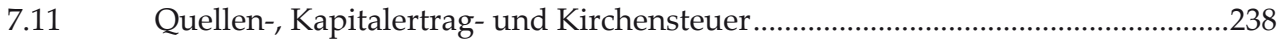

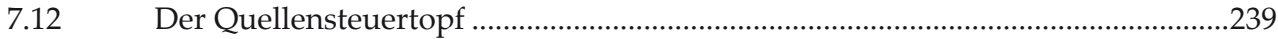

7.13 Das Führen von sogenannten „Schattentöpfen“

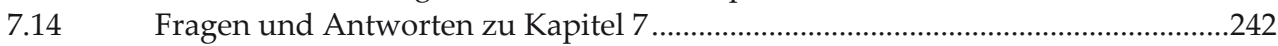

8 Das Steuerreporting von Banken gegenüber Kunden und Finanzbehörden .......245

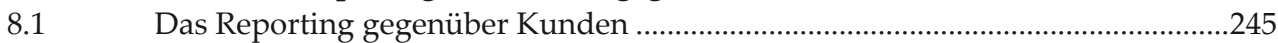

8.1.1 Das jährliche Steuerreporting von Banken in Deutschland ..................................245

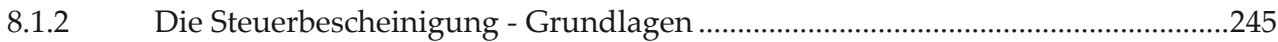

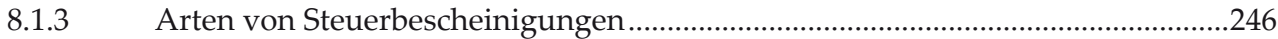

8.1.4 Einzelsteuerbescheinigungen versus Verlustverrechnung ....................................246

8.1.5 Das amtliche Muster I der Steuerbescheinigung ..................................................247

8.1.6 Muss die Steuerbescheinigung beim Finanzamt vorgelegt werden? ...................251

8.1.7 Wesentliche Merkmale der Steuerbescheinigung..............................................252

8.1.8 Die Verlustbescheinigung als Teil der Jahressteuerbescheinigung .......................253

8.1.9 Die Angabe des steuerlichen Gläubigers .............................................................254

8.1.10 Der Ausweis „Höhe der Kapitalerträge“ und der „davon-Positionen“................254

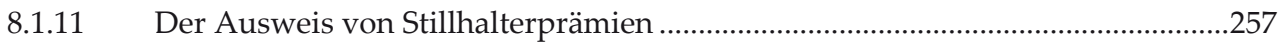

8.1.12 Der Ausweis von Ersatzbemessungsgrundlagen ..................................................258

8.1.13 Der Ausweis eines in Anspruch genommenen Sparer-Pauschbetrages ..............259

8.1.14 Der Ausweis der einbehaltenen Steuerbeträge ......................................................259

8.1.15 Der Ausweis von angerechneter und noch anrechenbarer ausländischer

Quellensteuer ...................................................................................................260

8.1.16 Leistungen aus dem steuerlichen Einlagekonto nach $\S 27$ KStG...........................262

8.1.17 Ausweis bei ausländischen Thesaurierungsfonds ................................................262

8.1.18 Das amtliche Muster III der Steuerbescheinigung ................................................265 


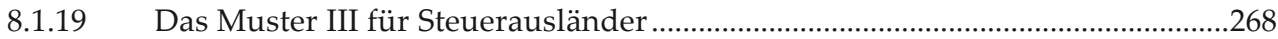

8.1.20 Die Verwendung von Muster III als Einzel- oder Jahressteuerbescheinigung ...268

8.1.21 Der Ausweis der Kapitalerträge und des Steuerabzuges für einen

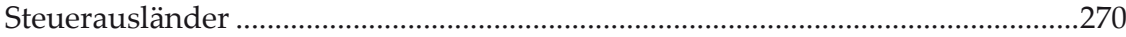

8.1.22 Die Erstellung von Ersatz- und berichtigten Steuerbescheinigungen ...................271

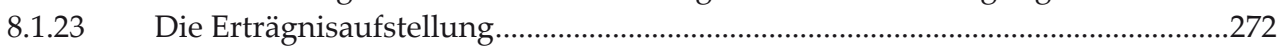

8.2 Das Reporting gegenüber den Finanzbehörden ...............................................272

8.2.1 Kapitalertragsteueranmeldung und -zerlegung .................................................272

8.2.1.1 Beispiele für die Kapitalertragsteueranmeldung und -zerlegung ........................278

8.2.2 Meldung betrieblicher Anleger mit Freistellungserklärung ...................................284

8.2.3 Meldung von Depotüberträgen..............................................................................28

8.2.3.1 Meldung unentgeltlicher Überträge (,Schenkungsmeldung“) .............................284

8.2.3.2 Meldung bei fehlender Kapitalertragsteuer-Bemessungsgrundlage.....................287

8.2.4 Meldung bei fehlendem Kapitalertragsteuereinbehalt nach $§ 44$ Abs. 1 Satz 7

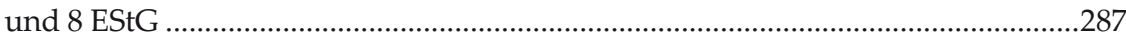

8.2.5 Meldung von Freistellungsaufträgen und Nichtveranlagungs-

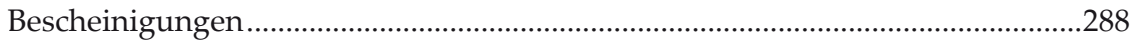

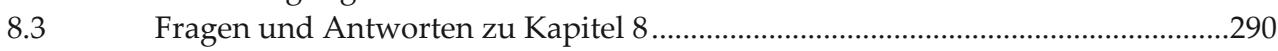

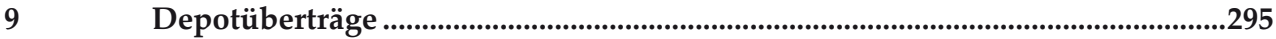

9.1 Die neue Systematik der Depotüberträge im Rahmen der Abgeltungsteuer......295

9.2 Wann handelt es sich um Depotüberträge mit Gläubigeridentität? .....................296

9.3 Wann handelt es sich um Depotüberträge mit Gläubigerwechsel?.......................296

9.4 Entgeltliche und unentgeltliche Depotüberträge .................................................296

9.4.1 Die steuerliche Behandlung von entgeltlichen Depotüberträgen .........................297

9.4.1.1 Die Bewertung des Depotausgangs bei entgeltlichen Depotüberträgen .............297

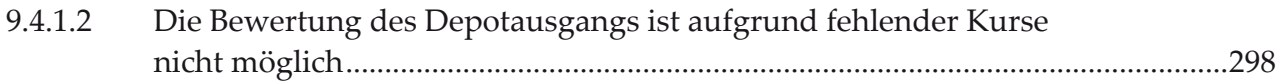

9.4.1.3 Die Bewertung des Depoteingangs bei entgeltlichen Depotüberträgen ...............298

9.4.2 Die steuerliche Behandlung von unentgeltlichen Depotüberträgen ....................299

9.4.3 Übertragung im Zusammenhang mit treuhänderisch geführten Depots............299

9.4.4 Unentgeltlicher Depotübertrag mit Gläubigerwechsel aus dem Ausland ...........300

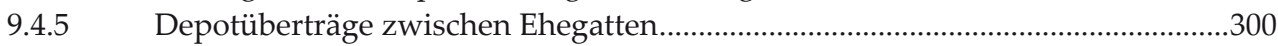

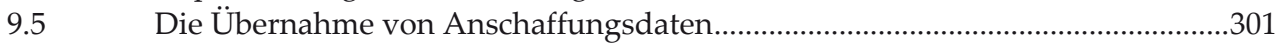

9.5.1 Die Übernahme von historischen Anschaffungsdaten ...........................................301

9.5.2 Arten der Übermittlung von Anschaffungsdaten .................................................302

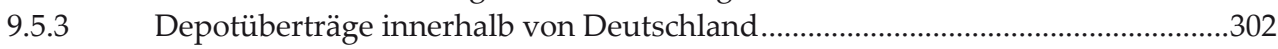

9.5.4 Die elektronische Übermittlung von Anschaffungsdaten innerhalb von

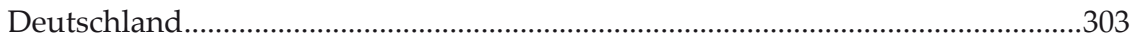

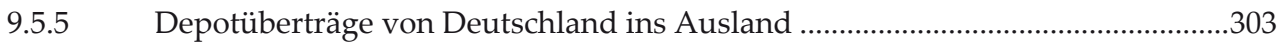

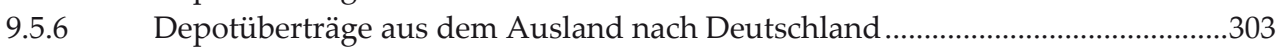

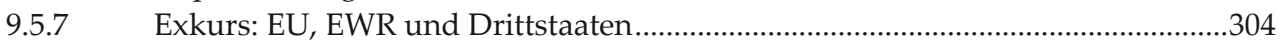

9.6 Die Systematik der Depotüberträge in Tabellenform ...............................................304

9.7 Depotüberträge vor 2009 - Meldung der Anschaffungsdaten ...............................306 
9.8 Welche Anschaffungsdaten müssen gemeldet werden? ........................................306

9.9 Was muss die aufnehmende Bank bei Übernahme der Daten beachten?..............308

9.10 Die Anforderung von Anschaffungsdaten aus dem Ausland ................................309

9.11 Die Berücksichtigung von Fondsdaten bei Einlieferungen aus dem Ausland....310

9.12 Die Übertragung von Verlustverrechnungs- und Quellensteuertöpfen ...............310

9.13 Korrekturen von Steuerdaten nach Übermittlung von Anschaffungsdaten

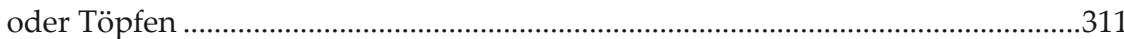

9.14 Anwendungsbeispiele zur Verdeutlichung der Übertragssystematik ..................311

9.15 Fragen und Antworten zu Kapitel 9 .....................................................................315

$10 \quad$ Die Bearbeitung von Nachlässen ............................................................................319

10.1 Die Komplexität von Nachlassfällen ...................................................................319

10.2 Der Bank wird bekannt, dass ein Kunde verstorben ist ..........................................319

10.3 Meldung gemäß § 33 Erbschaftsteuergesetz .............................................................320

10.4 Datum des Todes versus Datum der Kenntnisnahme durch die Bank .................320

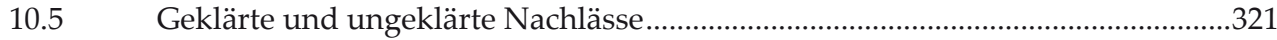

10.6 Verlustverrechnung und Quellensteueranrechnung bei Tod eines Kunden .......321

10.7 Übertragung der Konten und Depots auf die Erben...............................................322

10.8 Die Abgrenzung der Verlustverrechnung und Quellensteueranrechnung

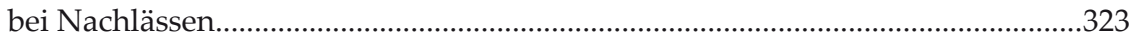

10.8.1 Konten und Depots von nicht ehelichen Gemeinschaftskonten ...........................323

10.8.2 Die Bescheinigung von Verlusten bei Nachlässen .................................................323

10.8.3 Rückwirkende Korrektur der Verlustverrechnung auf den Todestag ..................324

10.8.4 Die Anwendung der Ehegatten-Verlustverrechnung bei Tod eines Ehegatten .... 324

10.9 Die Bearbeitung von Freistellungsaufträgen bei Nachlässen .................................324

10.9.1 Besonderheit bei Freistellungsaufträgen ehelicher Gemeinschaftskonten

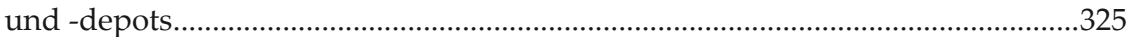

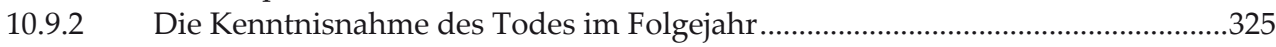

10.10 Die Bearbeitung von Nichtveranlagungs-Bescheinigungen bei Nachlässen........325

10.10.1 Besonderheit bei Nichtveranlagungs-Bescheinigungen von Ehepaaren ..............326

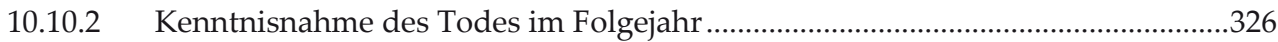

10.11 Beendigung des Kirchensteuereinbehaltes bei Nachlässen ..................................326

10.12 Kirchensteuereinbehalt bei nicht ehelichen Gemeinschaftskonten und -depots........ 326

10.13 Kontoumschreibungen und Vermögensüberträge bei Nachlässen .......................327

10.14 Die Erteilung von Steuerbescheinigungen bei Nachlassfällen ...............................327

10.15 Anwendungsbeispiele zur steuerlichen Behandlung von Nachlässen .................328

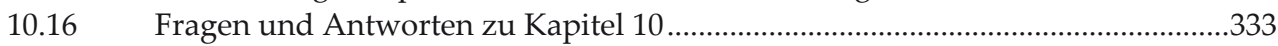

11 Die steuerliche Behandlung von Termingeschäften .........................................339

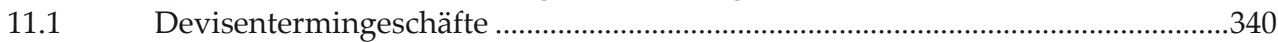

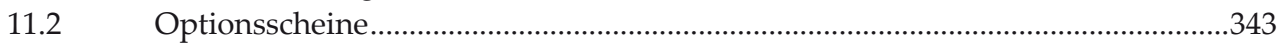

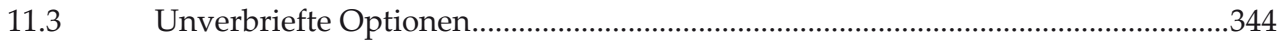

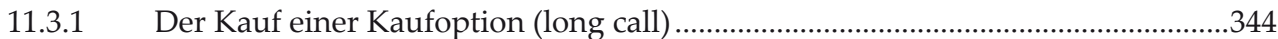

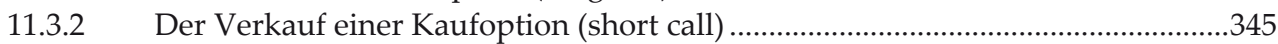




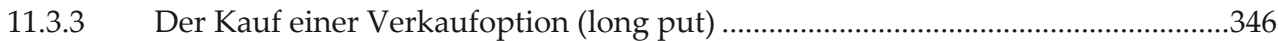

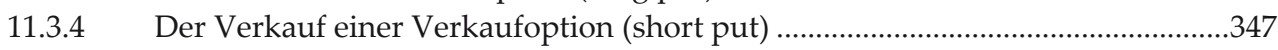

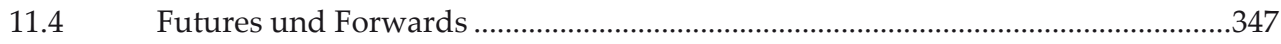

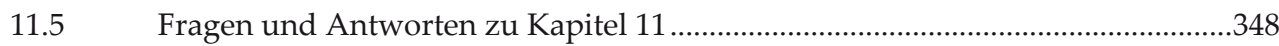

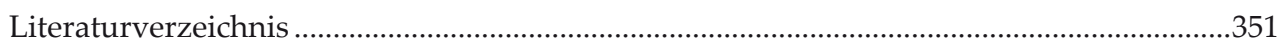

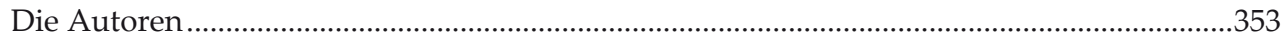

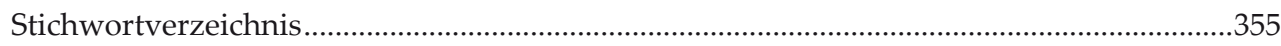

